\title{
THE APPROPRIATENESS OF GEOGRAPHIC INFORMATION SYSTEMS FOR REGIONAL PLANNING IN THE DEVELOPING WORLD
}

\author{
Richard E. Klosterman \\ Department of Geography and Planning, University of Akron, Akron, $\mathrm{OH}$
}

\begin{abstract}
This paper examines organizational and political issues associated with the use of geographic information systems (GIS) and land information systems (LIS) in the developing world. The paper suggests that "appropriate technology" for the developing world does not have to be oldfashioned or unsophisticated; it just has to be cheap, effective, reliable, and easy to use. As a result, the question of whether GIS technology is appropriate for regional planning in the developing world is dependent on the availability of all four components of the GIS technology "package": suitable equipment, appropriate information, proper organization, and available expertise. This paper considers each of these components as they relate to the use of GIS for regional planning in the developing world.
\end{abstract}

\section{INTRODUCTION}

Up-to-date and reliable information about the land, its characteristics, and its relation to a region's inhabitants is vital for the management of a country's human and natural resources, and for dealing with regional development and administrative decisions that have a spatial context. This information has traditionally been stored in manual records and displayed on paper maps that were expensive to prepare, hard to store, and very difficult to maintain, update, and analyze.

The advent of sophisticated geographic information systems (GIS) has greatly facilitated the storage, updating, retrieval, and display of spatial data that were previously maintained on paper. Their use facilitates the production of more useful information products, increases planners' ability to analyze spatially related phenomena, and helps provide the basis for more informed public and private decision making. Their usefulness results largely from their prodigious ability to manage spatially related data and the unrivaled effectiveness of maps for conveying spatially related information to users.

Experience in the industrialized world demonstrates that GIS are useful for a wide range of planning functions. Their extensive storage and retrieval capabilities provide a superior platform for maintaining land-based inventories and for organizing spatial data previously maintained by

Requests for reprints should be sent to Richard E. Klosterman, Department of Geography and Planning, Buchtel College of Arts and Sciences, University of Akron, Akron, OH 44325-5005, e-mail: klosterman@uakron.edu. 
different organizations and jurisdictions. Their ability to analyze different types of data stored in separate map layers is useful for identifying the optimal sites for land-related activities and for conducting land suitability and environmental impact analyses. Their ability to deal with spatial relationships are also extremely useful for spatial analysis tasks such as displaying district-related variables (e.g., average land values per hectare in different zones), identifying terrain characteristics (e.g., deriving slope and watershed maps), constructing corridors or buffers around selected map features (e.g., for conducting environmental impact studies), analyzing networkrelated transportation issues, and monitoring land-related changes over time (Marble \& Amundson, 1988; Webster, 1993, 1994).

GIS are particularly useful when used in conjunction with land information systems (LIS) containing current parcel-level data on property ownership, valuation, land use, development controls, and other land-related information. These data can then be used in a GIS to coordinate the maintenance of data collected by different government agencies, enhance property records by providing a visual dimension, expedite property-based inquiries by displaying them graphically, aggregate parcel-related data on the basis of spatial criteria, and facilitate the maintenance of property records and the preparation of property maps (Dueker \& DeLacy, 1990; Harris, 1990; Huxhold, 1991; Zwart \& Williamson, 1988).

GIS/LIS have been used to an increasing extent in many developing countries (United Nations Centre for Regional Development, 1988). In these settings, society's needs are the most pressing, public resources are extremely limited, and experience with advanced information technology was, until quite recently, almost nonexistent. As a result, the developing world provides the greatest opportunities for — and the most significant obstacles to - using advanced computer-based tools such as GIS/LIS in regional planning (Mannheim, 1987).

This paper will examine organizational and political issues associated with the use of GIS/LIS systems in the developing world. The paper starts from the premise that "technology" consists not merely of tools and machines but of four interdependent components: (1) equipment, the tools, instruments, and machines used to perform a particular set of tasks; (2) technique, the specialized skills, procedures, methods, and policies employed in using a particular piece of equipment; (3) organization, the formal and informal relationships between the individuals and groups that utilize a particular piece of equipment and related techniques; and (4) knowledge, the supplemental information about the physical and social world required to employ a particular set of equipment, technique, and organization effectively (Danziger, Dutton, Kling, \& Kraemer, 1982).

This broader perspective has proven extremely useful in a number of studies of the adoption and use of information technology conducted in the United States over the last 20 years (see, for example, Danziger et al., 1982; Dutton \& Kraemer, 1985; King \& Kraemer, 1985). In the present context, it suggests that "appropriate technology" for the developing world does not have to be old-fashioned or unsophisticated; it just has to be cheap, effective, reliable, and easy to use (Cartwright, 1990, p. 265). Thus, the question of whether GIS technology is appropriate for regional planning in the developing world is dependent on the availability of all four components of the GIS technology "package": suitable equipment, appropriate information, proper organization, and available expertise. This paper will examine these four components as they relate to the use of GIS for regional planning in the developing world.

\section{SUITABLE EQUIPMENT}

Dramatic advances in the realm of microcomputer technology have replaced the expensive and delicate mainframe computers of the 1960s and ' $70 \mathrm{~s}$ with independent systems that are ideally suited for use in the developing world. Microcomputers are becoming smaller, more rugged, and increasingly reliable, allowing them to used - and manufactured — throughout the developing world. 
They are relatively easy to use, substantially reducing the need for technical resources and trained personnel that are extremely scarce in the developing world. They are highly adaptable and can be used for applications ranging from word processing and record keeping to computer-based mapping and GIS. Most importantly, they are inexpensive - and become cheaper every year. If current trends continue, microcomputers will soon be available in the developing world for $\$ 100$ or less, allowing every one of India's 600,000 villages to be equipped with a computer for less than the cost of a dozen fighter aircraft (Harris, 1989).

The increased availability of computer hardware in the developing world is not enough, of course; GIS software is also required. GIS/LIS systems were first developed in the $1960 \mathrm{~s}$ with the increased availability of mainframe computers and graphics terminals. However, these pioneering efforts were restrained by the limitations of available hardware platforms and the lack of reliable software. The major breakthroughs in the cost, speed, and storage capacities of computer hardware and dramatic advances in GIS/LIS software of the 1980s and 1990s have made GIS both practical and affordable. These advances have spawned a lucrative and growing market for GIS technology and dozens of GIS programs ranging from minicomputer systems costing more than $\$ 20,000$ to microcomputer-based packages costing less than $\$ 500$.

Minicomputer GIS with dedicated workstations and sophisticated software such as ARC/INFO and ERDAS can obviously handle larger data sets more quickly, produce better graphic output, and provide more sophisticated analytic capabilities than systems operating on a microcomputer. However, it is equally clear that these sophisticated systems are well beyond the budgets of planning agencies in most developing counties, with the possible exception of central governments and primary cities. Fortunately, microcomputer-based GIS now provide most of the capabilities that were available only on UNIX-based workstations just a few years ago (Landis, 1990). ${ }^{1}$ As a result, the lack of GIS software is no longer an overwhelming obstacle to the use of GIS by national and regional agencies in many developing countries.

\section{APPROPRIATE INFORMATION}

An examination of the role of information in the acquisition and dissemination of geographic information for regional planning must begin by recognizing the fundamental difference between data and information. Data are numerical or symbolic representations that attempt to describe the attributes of people, organizations, objects, events, or concepts. Information is data which have been structured, organized, summarized, or transformed so that they will increase the user's understanding of the phenomenon being considered (Harris, 1987; Nijkamp, 1983). Thus, the ultimate value of a geographic information system lies in its unparalleled ability to store, manipulate, integrate, and display geographically referenced data, that is, to transform raw observation data into information that can be understood more readily by planners and decision makers. They are particularly valuable because information on spatially related objects and actions can be presented and understood much more rapidly when they are displayed on a map than when they are reported in a table or described in a text.

\section{Data Collection Alternatives}

A range of techniques can be used to collect the spatial information required to implement a GIS/LIS system. Ground surveys are straightforward, easy to conduct with untrained personnel,

\footnotetext{
'Another potentially useful strategy for GIS applications in developing countries is represented by the Computer Assisted Regional Planning (CARP), a loosely linked modular system that uses a set of BASIC-language linker routines to integrate a widely used computer-aided drafting package (AutoCAD) with an equally popular database manager (dBASE) to provide a low-cost GIS system (Yapa, 1988, 1989).
} 
and relatively accurate because land features are observed directly. However, they may take a long time to complete because the resulting paper maps and records must be processed by hand for storage in a GIS.

Aerial photography provides a useful surrogate for direct observation, allowing the mapmaker to prepare land-use maps in the convenience of an office. This allows geographically referenced data to be collected quickly and provides a permanent record of the current landscape. Projects conducted by the International Institute for Aerospace Survey and Earth Sciences (ITC) demonstrate that air photo interpretation can be used in conjunction with GIS techniques to provide an effective data-collection tool in many developing countries (de Bruijn, 1990).

Satellite and airborne remote-sensing technologies are also useful for providing synoptic, repetitive, and current views of the Earth's surface. They are particularly useful because they can be combined with ancillary data stored in a GIS to greatly improve the speed and efficiency of detecting urban change and updating maps and related attribute data. Prototype systems that combine satellite remote-sensing data with a conventional GIS running on a microcomputer have been developed and used successfully in the developing world (Seong, 1991).

Low-cost, hand-held global positioning systems (GPS) are also available that use special receivers and geodetic control satellites to automatically record the receiver's latitude, longitude, and altitude. These units can be mounted on vehicles and used to quickly and easily collect current and accurate location and attribute data that can be loaded directly into a GIS. The technology is still rather expensive but should soon prove useful in much of the developing world.

\section{Obstacles to Data Collection}

Once it is recognized that a GIS is only a tool for storing, manipulating, and displaying spatially related data, it is clear that data availability and quality are essential components of an GIS system. Accurate information can only be generated by the system if the data on which it is based are accurate to begin with. If the data are inaccurate or incomplete, the use of sophisticated GIS technology will only be an expensive graphic and spatial version of "garbage in, garbage out."

In developed countries, data on land ownership, land use, and the location of public and private facilities are readily available or can be obtained from permits, licenses, and tax records. However, public agencies around the world are discovering that much of these data are outdated, inconsistent, incomplete, designed only for administrative or regulatory purposes, and very difficult to integrate. Data collection and integration are particularly time consuming and expensive when local governments attempt to collect the parcel-level data required by a comprehensive LIS. As a result, experience in the industrialized world reveals that construction of the database is the largest expenditure in implementing a GIS with costs that are commonly five to ten times those of the hardware and software. Creating the database requires the collection of required data, the organization and integration of existing data, and the conversion of these data into suitable digital form. All of these tasks are time consuming, labor intensive, and quite expensive. The resulting database is therefore an extremely valuable corporate asset not only because of the data it contains but also because the data are now more accessible, consistent, accurate, and usable for a much wider range of applications (Worrall, 1989).

Case studies of data-collection efforts in the developing world (e.g., United Nations Centre for Regional Development, 1986, pp. 305-490) reveal that the lack of adequate data is particularly severe in these settings. A considcrablc amount of social and economic data has been collected at a national level, but very little has been collected on a local or regional level. Local and regional governments often have very limited data-collection capacities, particularly for obtaining data on current land uses. The data that are collected are often not collected system- 
atically and are not consistent with respect to time, geographic coverage, or definition, making data integration extremely difficult (Edralin, 1986, p. 506).

Large-scale base maps are often unavailable. When available, they are often extremely out of date, making them of limited use for monitoring the rapid, unplanned, and unregulated growth of larger cities in developing countries. The most readily available spatial data in much of the developing world have been collected through remote-sensing techniques that deal primarily with land cover and the physical environment. As a result, socio-economic and land-ownership data that are essential for urban and regional planning efforts are generally lacking; the data which are available are often limited to census data.

The difficulty of collecting accurate and current information on a region's current population and land-use patterns is compounded by the existence of a large "informal sector" in much of the developing world that resists the collection of more reliable information in the fear that it will be used against them. Data-collection efforts are also frustrated by antiquated, understaffed, and inadequately funded municipal and district data collection and storage systems that cannot keep pace with constantly growing data volumes (de Bruijn, 1990).

Even the information collected by government can be extremely difficult to obtain in many developing countries. Many countries view "official" information as confidential. Some countries restrict access to information related to financial, commercial, and trade topics where speculation might take place. Other countries treat data on geological or natural resources obtained by aerial surveys and remote sensing as military secrets. In others, politically sensitive information is used with extreme caution or suppressed entirely (Edralin, 1986, pp. 491-533). While these obstacles cannot be overcome by technical advances, developments in the former Soviet block and elsewhere provide room for some optimism.

The lack of current data is compounded by issues of data quality. The data that are available are often woefully out of date, severely limiting their appropriateness for current planning efforts. The data that have been collected are often collected by other local and regional agencies without any concern for their appropriateness for planning. In addition, there is a general lack of organizational procedures for monitoring and coordinating the frequency of data updating or for verifying the data that are collected (Yeh, 1991).

The lack of consistent and reliable data results from the severe resource limitations, inadequate systems designs, and the shortage of skilled personnel and technical expertise that are found throughout the developing world. They also reflect a lack of appreciation on the part of policy makers, project managers, planners, and other staff for the value of and uses for computer-based information systems (Edralin, 1986, p. 524).

Ironically, the ability of modern GIS/LIS methods to collect and store land data more accurately than was possible before creates as many problems as it solves. The newly acquired location and attribute data are much more reliable than the data that were obtained previously with traditional, largely manual, techniques. Previously existing data - while inevitably inaccurate - were recorded on paper maps and stored in manual files that obscured the inaccuracies and conflicts in the data. The automated data collection and storage procedures provided by a comprehensive GIS/LIS are therefore very useful for revealing the unrecognized problems in the current data. However, they provide little help in correcting these problems, because the errors are often embedded in legal records that cannot be altered on technical grounds, without some kind of legal procedure (Werle, 1984, pp. 199-202).

\section{Need for an Incremental System-Development Strategy}

The difficulty of developing an up-to-date and reliable land records database makes it essential that developing countries adopt a staged process of GIS development. A "one step at a time" system development process recognizes the importance of learning by doing and 
maintaining the flexibility needed to adapt to future changes in user needs and technology. This strategy recognizes that it is better to have a modest system in use than an elaborate one that remains "on the drawing boards" going through a never-ending process of refinement. It also acknowledges that an information system should serve the current needs of data users because it may not be possible - or desirable - to anticipate how the system will be used until there is some experience with it.

Early system output that are useful for improving current operations are particularly important for demonstrating the system's usefulness and for revealing the potential benefits - and costs - of further developments. Initial products should be important but not essential so that the results are seen as valuable and unexpected delays are not catastrophic. Each system enhancement should ideally be designed so that it will link easily with existing system components and be compatible with future enhancements; the goal is to "design holistically, but implement modularly" (Godschalk, Bollens, Hekman, \& Miles, 1985, pp. 96-97; Masser \& Campbell, 1991).

An incremental development strategy also imposes fewer demands on leadership, staff commitment, and technical resources and is less vulnerable to organizational and environmental changes because changes can made relatively quickly. Getting a system into operation as soon as possible not only helps win support for the system; it may also help pay for the system if it helps generate increased revenues from property taxes and other funding sources (Cartwright, 1990, p. 117).

The value of a step-by-step implementation strategy is reinforced by experience in the United States which suggests that implementation success, in terms of real system use, most often occurs when systems provide immediate applications that public officials and senior management value. The most popular systems have often been some of the simplest, such as straightforward permit-tracking systems that are immediately useful for improving the permitting process, expediting information requests, and monitoring the current housing inventory (Innes, Steiner, \& Landis, 1989).

The data-management plan must also recognize that GIS needs, capacities, and applications will inevitably change over time. GIS are often acquired initially to collect more information about a particular policy issue or to solve practical problems that have been encountered in dealing with existing manual and paper-map-based land information systems. The new technology is generally used first to perform traditional tasks in "old" ways with new tools. Later, as familiarity with the technology is gained, new ways of providing the same functions are developed that more fully take advantage of the technology.

As the information and experience base improves, systems applications become more sophisticated, data requirements become more specialized, and the technical aspects of the system may overshadow or even divert attention from the original development purpose. Eventually, entirely new data management and analysis approaches are developed that take full advantage of the potential offered by the new technology. In the case of GIS, the first applications tend to be collecting and inventorying current data. Later, the emphasis shifts to satisfying analysis requirements, and finally, to addressing management and policy-making needs (Huxhold, 1991, pp. 12-23; le Clercq, 1988).

As a result, the GIS development effort in most developing countries should begin by converting existing manual permit procedures to forms-based systems utilizing a microcomputer database manager. These systems can be implemented quickly and easily, allowing management functions and public services to be improved while simultaneously accumulating the data needed for monitoring and planning. The data collection and organization effort may take 5 years or more and can proceed in parallel with the effort to establish a GIS.

As expertise accumulates, the data can be analyzed with electronic spreadsheets, and spatial patterns in the data can be examined with low-cost thematic mappers. Later on, the data can be 
entered into a microcomputer-based GIS maintained, at least initially, by a single local agency. Ultimately, the combined GIS/LIS should be part of a comprehensive municipal or regional information system to insure overall coordination and a continuous supply of good quality, upto-date location and attribute data (de Bruijn, 1990).

The staged development effort should be part of an overall information management strategy that accounts for data availability, computing capacities, and management requirements. Without this, major problems in computer utilization will inevitably arise as a result of mismatches between information needs and data availability and between data-collection procedures and information-processing requirements. The potential for problems is particularly high in developing countries where the receiving agency generally has little experience with computerized systems and the system is installed with the help of international aid. It is generally assumed in these settings that recurring system operation and enhancement costs will be acquired from local funding sources; unfortunately, these are often unavailable, dooming the effort to failure (Masser \& Campbell, 1991, p. 64).

The management strategy must also recognize that while database creation is expensive and time consuming, it is even more expensive and often practically impossible to modify the data structure after it is in operation. As a result, poorly designed or managed computer-based information systems are often less productive - and more expensive - than the manual systems they replace and are likely to cause more problems than they solve.

The data-management plan must define: (1) management policies for the coordinated development and maintenance of the GIS software, database, and applications; (2) procedures for data collection, processing, analysis, retrieval, and dissemination; (3) employment and working conditions for the GIS technical staff; and (4) guidelines for data access and data protection. All of these issues will arise in the GIS development process and can be dealt with more effectively if they are anticipated in advance. The establishment of a national or regional GIS center can be particularly helpful for coordinating system-development efforts throughout all levels of government, promoting the development of uniform information-system policies, and providing valuable technical advice and support services (Suzuki, 1986).

It is also essential that the data-management plan define and enforce strict procedures for data documentation. The documentation should be integrated closely with the data and describe the data source or collection procedure, the collection date, and the methods used to cncodc the data. The documentation should ideally provide complete information on data quality including such factors as the data's positional and attribute accuracy, its resolution and completeness, and any conditions imposed on its utilization and dissemination. This information is essential for recording the data history and for allowing future users to assess its suitability for specific applications (Aronoff, 1989, pp. 133-144).

\section{PROPER ORGANIZATION}

Substantial investments are being made to acquire GIS technology in the third world; however, it is not clear that these systems are functioning satisfactorily or contributing to national or regional development efforts. This experience reflects the degree to which technology transfers of this type are initiated by suppliers rather than receivers and the failure to take adequate account of the organizational setting and motivations of those involved. Under these circumstances, bureaucratic inertia, political instability, and personal cynicism are often critical constraints on the effective utilization of the new technology (Drummon \& Stefanovic, 1986; Masser \& Campbell, 1991, p. 60).

Experience with GIS systems in the industrialized world reveals that implementation failures are almost always the result of people problems, not technical problems. The capabilities and limitations of technical tools can be evaluated by means of physical tests, and the results can be 
expected to be repeatable. Many technical problems can therefore be anticipated and handled with contingency plans; others can be resolved by adding additional equipment or by calling on outside technical expertise.

The actions of people are much less predictable because they are influenced by organizational, personal, and political factors that often take precedence over technical considerations. ${ }^{2}$ As a result, technical personnel must be constantly aware that technical efficiency is rarely a sufficient reason for adopting computer-bascd technologies, particularly if they threaten the existing balance of power within the organization or the career paths - and remuneration - of individuals (Calhoun, Drummond, \& Whittington, 1987, pp. 370-372).

GIS implementation, like any important bureaucratic initiative, requires the sustained efforts of an organizational advocate who is willing and able to provide the direction needed to make the project succeed. More importantly, the active support of senior management is essential for acquiring the financial and personnel resources needed to initiate the development effort and to insure continued support in the future (Aronoff, 1989, p. 249; Budić \& Godschalk, 1994; Godschalk et al., 1985, p. 88).

The system development process is often assumed to proceed in a step-wise fashion. First, management establishes system goals. Technicians then ask users to define their needs and select or create a system to suit these needs. Finally, planners and other analysts use the system.

Studies of successful - and unsuccessful - system-development efforts reveal that this process rarely works, because each group lacks the information needed to act appropriately. Senior management has a sense of political and organizational realities but does not know what is technically realistic or operationally feasible. Technicians understand the technical possibilities but do not know what is politically desirable or operationally necessary. Planners may not know what is technically feasible or politically desirable; however, they are the only ones who are familiar with planning issues and the details of their work.

Unfettered communication and mutual learning involving system users, senior management, and technical experts are therefore essential for successful system implementation. User participation is strategically important because they will provide much of the required data and their involvement reduces the potential for later criticism. It is also operationally helpful because users are generally the best prepared to identify available resources and personnel and warn of potential organizational problems (Godschalk et al., 1985, p. 94; Innes et al., 1989; Masser \& Campbell, 1991, p. 66).

As a result, the system design should begin by determining how current operations are being carried out so that user needs can be incorporated into the final system specifications. This information should be obtained by a user-requirements study which identifies: (1) the organizational responsibilities of data users, (2) the procedures and equipment used to carry out these responsibilities, (3) the geographic data currently being used or generated by users, (4) existing resources, and (5) the potential for introducing new technology in the future. The understanding obtained through this survey can then be used to define the data collection, organization, storage, and management procedures to be incorporated into the final system design. Structured system-design methodologies are particularly helpful in this regard (Wiggins \& French, 1991).

\section{Political Impact of GIS Technology}

By providing more information, more quickly, and in more readily accessible forms, GIS technology will not only allow planning organizations to perform old tasks more efficiently, it will also require them to handle new types of data in new ways, work with more sophisticated

${ }^{2}$ The lack of financial resources to acquire equipment or technical advice is only another type of "people problem." 
equipment, hire more highly trained personnel, and deal with new organizational clientele. More importantly, the adoption of a pervasive new technology like GIS will affect the production and distribution of information - and thus power - within government as different people exert varying degrees of control over geographically referenced information. As a result, computer-assisted technical tools like GIS are inherently political because they help determine who gets what, when, and how. They also tend to be inherently conservative - increasing the power of administrators and technical experts, reinforcing existing structures of influence, and strengthening bureaucratic control over government departments (Danziger et al., 1982; Dutton \& Kraemer, 1985; Jacobs, 1989; Laudon, 1974).

Information systems are particularly powerful organizational tools because information is often viewed as more accurate, credible, and "objective" simply because it has been generated by a computer. This perception fails to recognize that the development and use of an information system necessarily involves fundamentally political choices with regard to the selection of data, the application of computational procedures, and the analysis, presentation, and distribution of results. As a result, GIS and related computer-assisted analysis tools can be used to provide a technological form of "mystification through automation," burying inherently political choices within technical analyses unfathomable to outsiders (Klosterman, 1987; Wachs, 1982). More fundamentally, the increased use of computer-aided tools like GIS tends to focus public attention on policy questions that can be more readily incorporated into a GIS database and away from those that cannot be easily measured, counted, or mapped (Innes, 1988; Tribe, 1972; Weizenbaum, 1976, pp. 228-257, 448-453).

Experience also suggests that the GIS implementation and adoption process is not a straightforward technical process of model development, introduction, and use. Instead, it often becomes a focus for political dispute, negotiation, and bargaining as system developers, agency personnel, senior management, and public officials wrestle with the fundamentally political questions of identifying the most appropriate system design, the data it should contain, the types of analyses to be performed, and the policies to be used for disseminating the analysis results (Adler, 1987; Dutton \& Kraemer, 1985).

Merely converting information from paper records to digital form can itself have important political implications. Property information stored in digital form can be used to generate information that would be impractical to obtain when the same data are available in hand-written entries. For example, identifying the 100 largest property holders in a city or locating all land parcels within a kilometcr of a hazardous waste site would be extremcly difficult with paper maps and manual records but quick and easy with a GIS. As a result, the greatly enhanced ability to store and access information that GIS provides increases the potential for information abuse and misuse, raising fundamental issues of data security, reliability, and responsibility (Aronoff, 1989, pp. 269-277).

\section{AVAILABLE EXPERTISE}

It is not enough to purchase a computer, a plotter, a display device, and some GIS software and put them in the corner with some enthusiastic personnel and then expect immediate returns. A serious commitment to GIS requires a major investment by the whole organization; it must be prepared to deal with different types of data, to deal with these data in new ways, and to produce different types of outputs. More importantly, new types of staff must be hired, and new organizational units must be created to support the new system (Burrough, 1986, p. 170).

Attracting and retaining personnel is essential for rapidly changing technical fields such as GIS where necessary expertise is scarce and continuity is essential for accumulating the operational experience needed to operate the system. As a result, the management environment of a 
GIS facility has been correctly identified as "perhaps the most important single factor in determining its success or failure" (Aronoff, 1989, p. 44).

Personnel is important because a GIS system requires many types of people with a wide range of skills. At one end, the system requires low-skilled staff (typists, computer operators, map digitizers, etc.) who may not understand how the GIS works but are needed to keep it operating smoothly. System managers and liaison personnel are also needed to supervise the daily operation of the system and to maintain a harmonious interaction with the rest of the organization. Trained and experienced system programmers and developers are required to bring the system to the required operating level and to deal with day-to-day glitches that are common to any computer installation. Most importantly, the system needs experienced and well-trained planners and analysts to determine what types of information should be collected and to interpret and use the information that is provided (Burrough, 1986, pp. 256-257).

\section{Need for Information and Training}

The need for trained and experienced GIS staff poses particularly severe obstacles in developing countries whose inability to attract and retain qualified personnel in the public sector is well-known and widespread (Sadowsky, 1989). Governments everywhere can rarely match the salaries and fringe benefits offered by private industry, particularly for GIS technicians that are in increasingly great demand in both the public and private scctors. Retaining technical personnel is even more difficult because people can often be brought into the public sector at fairly low levels. However, they soon gain skills and experience that allow them to move to more lucrative jobs with other government agencies or in the public sector.

Budget constraints and bureaucratic red tape often make it difficult for government to provide attractive opportunities for working with the latest hardware and software. The rigidities of public personnel systems often lag far behind technical advances in the field of computer technology. As a result, job titles, descriptions, qualifying examinations, and promotion standards frequently do not match the work actually being performed, causing severe problems for managers and employees alike.

All of these factors discourage qualified technical personnel from entering the public sector and encourage them to leave, creating a perpetual need for finding and training new personnel. The effect of the world-wide shortage of professional personnel with data processing and GIS skills is much more severe in the developing countries that do not have a critical mass of specialists to begin with. As a result, filling a vacancy may require a long time and may stall progress on a project indefinitely (Moskovitz \& Mammen, 1986).

The lack of technical expertise in the developing world is exacerbated by the difficulty of accessing the rich flow of information about technical issues, products, and reports of experiences available in the industrialized world. Delivery of printed materials is delayed by distance. International mail rates are high. Limited foreign exchange may not available for purchasing these materials. Local postal systems are often unreliable. The lack of technical expertise constrains the ability to comprehend the material that is available and to adapt it to the local environment. In addition, the lack of information on developments in other settings is often not noticed, and old techniques and procedures are continued without a knowledge that alternatives exist (Sadowsky, 1989, p. 275).

Many individuals in the developing world could benefit from specialized technical training abroad. However, the primary need is for more basic training of large numbers of people within the country to provide the general skill levels required for the effective use of advanced information technologies. Planning professionals and GIS personnel must be trained in the details of conducting basic system operation tasks. More importantly, they must be made aware of the assumptions and limitations of the models, methods, and data they use, become familiar with 
alternative approaches for dealing with information, and recognize the political implications of their practice (Klosterman, 1990).

The need for advanced technical training is not being met adequately in the developing world because education is a labor-intensive activity requiring skilled manpower with substantial real and opportunity costs. A range of dissemination mechanisms will be required to help meet these needs. National and multinational training and demonstration centers must be established to provide essential hands-on experience with GIS tools and techniques. Visits by outside experts knowledgeable in GIS applications, the facilities of local universities, and the knowledge of in-country experts can also used to expand the local knowledge base. Current information on GIS hardware, software, publications, and data can also be made available through specialized magazines and newsletters, working papers, software catalogs, and international conferences (Klosterman, 1988; Sadowsky, 1989, pp. 275-277).

\section{CONCLUSIONS}

GIS technology is attracting a great deal of interest in both the industrialized and developing worlds. This interest reflects the technology's demonstrated utility for a wide range of geographically related applications and the allure of sophisticated graphics technology and highpowered marketing. As a result, for many organizations, GIS seems to provide a new and exciting technology that will quickly remove many of the problems inherent in conventional methods of spatial data analysis and regional planning.

However, it must be remembered that new technologies always bring new problems and rarely live up to expectations. A GIS is very expensive to implement and is often more expensive - at least in the short term - than the conventional methods it replaces. The cost of cleaning existing data, converting it to digital form, and filling in data gaps and deficiencies is usually many times larger than the combined cost of hardware and software. GIS also impose substantial - and often unforeseen - monetary and personnel overhead costs for establishing and maintaining the system.

These costs are more easily justified if the data volumes are large, the data must be frequently accessed, updating the data is important, and the data will be used repeatedly for a wide range of analyses. Few of these conditions currently apply to regional planning efforts in the developing world (Aronoff, 1989, p. 44; Burrough, 1986, p. 170).

It must also be remembered that developments in GIS are largely technology-driven and are taking place in isolation from, and faster than, developments in the planning processes, analysis tools, and data collection procedures required to use them effectively (Harris, 1989; Harris \& Batty, 1993; Worrall, 1989). This is particularly true in the developing world where resources are severely limited, spatially related data are hard to obtain, technical expertise is in short supply, and organizational support is extremely limited.

In these settings, it is essential that planners focus their attention on the data infrastructure which supports the system, adopt a modest incremental implementation process, and pay as much attention to personnel and organizational considerations as they do to issues of hardware and software. If they do not, GIS will only be another expensive and short-lived fad that does little to address the real needs of the developing world.

\section{REFERENCES}

Adler, S. (1987). The new information technology and the structure of planning practice. Jeurnal of Planning Education and Research, 6, 93-99.

Aronoff, S. (1989). Geographical information systems: A management perspective. Ottawa: WDL Publications.

Budic, Z. D., \& Godschalk, D. R. (1994). Implementation and management effectiveness in adoption of GIS technology in local governments. Computers, Environment and Urban Systems, 18(5), 285-304. 
Burrough, P. (1986). Principles of geographic information systems for land resource assessment. Oxford: Clarendon Press.

Calhoun, C., Drummond, W., \& Whittington, D. (1987). Computerised information management in a systeins-poor environment: Lessons from the design and implementation of a computer system for the Sudanese Planning Ministry. Third World Planning Review, 9(4), 361-379.

Cartwright, T. J. (1990). The management of human settlements: Case studies in the application of microcomputers. London: Routledge.

Danziger, J. N., Dutton, W. H., Kling, R., \& Kraemer, K. L. (1982). Computers and politics: High technology in American local governments. New York: Columbia University Press.

de Bruijn, C. A. (1990). New systems, other methods: The introduction of LIS and GIS for urban planning. Regional Development Dialogue, $11,95-116$.

Drummon, J., \& Stefanovic, P. (1986). Transfer of high technology to developing countries. In M. Blakemore (Ed.), Proceedings, Auto Carto London (Vol. 2: Digital Mapping and Spatial Information Systems). London: Auto Carto.

Dueker, K. J., \& DeLacy, P. B. (1990). GIS in the land development planning process: Balancing the needs of land use planners and real estate developers. Journal of the American Planning Association, 56(4), 483-491.

Dutton, W. H., \& Kraemer, K. L. (1985). Modeling as negotiating: The political dynamics of computer models in the policy process, Norwood, NJ: Ablex Publishing.

Edralin, J. S. (1986). Critical perspectives on information systems for urban and regional planning. In United Nations Centre for Regional Development (Ed.), Information systems in urban and regional planning: Asian and Pacific perspectives (pp. 491-531). Nagoya, Japan: United Nations Centre for Regional Development.

Godschalk, D. R., Bollens, S. A., Hekman, J. S., \& Miles, M. E. (1985). Land supply monitoring: A guide for improving public and private urban development decisions. Boston: Oelgeschlager, Gunn \& Hain.

Harris, B. (1987). Information is not enough. URISA News, 90, 4-5, 23.

Harris, B. (1989). Beyond geographic information systems: Computers and planning profession. Journal of the American Planning Association, 55, 85-92.

Harris, B. (1989). Does the third world need computers? Environment and Planning, B: Planning and Design, 16, 371-376.

Harris, B. (1990). Urban and regional planning in the third world with geographic information system support. Regional Development Dialogue, 11, 17-57.

Harris, B., \& M. Batty. (1993). Locational models, geographical information, and planning support systems. Journal of Planning Education and Research, 12(3), 184-198.

Huxhold, W. E. (1991). An introduction to geographic information systems. New York: Oxford University Press.

Innes, J. (1988). The power of data requirements. Journal of the American Planning Association, 54, 275-278.

Innes, J. E., Steiner, R., \& Landis, J. D. (1989). Computing in planning agencies: Case studies in implementation. Cambridge, MA: Lincoln Institute of Land Policy.

Jacobs, H. M. (1989). Implementing local multipurpose information systems: Political-economic research issues. Computers, Environment and Urban Systems, 13, 3-14.

King, J. L., \& Kraemer, K. L. (1985). The dynamics of computing. New York: Columbia University.

Klosterman, R. E. (1987). Politics of computer-aided planning. Town Planning Review, 58(4), 441-452.

Klosterman, R. E. (1988). Microcomputer technology and regional planning in the developing world. Computers, Environment and Urban Systems, 12, 114-115.

Klosterman, R. E. (1990). Microcomputers in urban and regional planning: Lessons from the past, directions for the future. Computers, Environment and Urban Systems, 14(3), 177-185.

Landis, J. D. (1990). Microcomputer-based GIS systems. Journal of the American Planning Association, 56(3), 373-374.

Laudon, K. C. (1974). Computers and bureaucratic reform: The political function of urban information systems. New York: John Wiley.

le Clercq, F. (1988). Evaluating the state of information systems in Amsterdam. In United Nations Centre for Regional Development (Ed.), Information systems for government and business: Trends, issues, challenges (pp. 249-256). Nagoya, Japan: United Nations Centre for Regional Development.

Mannheim, M. L. (1987). The third computer revolution: Implications for training in developing countries. Regional Development Dialogue, $8,122-140$.

Marble, D. F., \& Amundson, S. E. (1988). Microcomputer-based geographic information systems and their role in urban and regional planning. Environment and Planning, B: Planning and Design, 15, 306-309.

Masser, I., \& Campbell, H. (1991). Conditions for the effective utilization of computers in urban planning in developing countries. Computers, Environment and Urban Systems, 15(1), 55-67.

Moskovitz, D., \& Mammen, D. (1986). Information technologies in government: Organizational and management issues. In United Nations Centre for Regional Development (Ed.), Information systems for urban and regional planning: Asian and Pacific perspectives (pp. 174-176). Nagoya, Japan: United Nations Centre for Regional Development.

Nijkamp, P. (1983). Information systems for regional development planning: A state-of-the-art survey. Environment and Planning, B: Planning and Design, I0, 283-302.

Sadowsky, G. (1989). Statistical data processing in development countries: Infrastructure consideration. Computers, Environment and Urban Systems, 13(4), 269-289.

Seong, K. T. (1991). Integrating GIS and remote sensing for urban and regional planning. In R. E. Klosterman (Ed.), Proceedings: Second International Conference on Computers in Urban Planning and Urban Management (pp. 265-279). Akron, OH: University of Akron, Institute for Computer-Aided Planning. 
Suzuki, I. (1986). Applications of information systems in public administration. In United Nations Centre for Regional Development (Ed.), Information systems in urban and regional planning: Asian and Pacific perspectives (pp. 137-161). Nagoya, Japan: United Nations Centre for Regional Development.

Tribe, L. H. (1972). Policy science: Analysis or ideology? Philosophy and Public Affairs, 2, 66-110.

United Nations Centre for Regional Development. (1986). Information systems for urban and regional planning: Asian and Pacific perspectives. Nagoya, Japan: Author.

United Nations Centre for Regional Development. (1988). Information systems for government and business: Trends, issues, challenges. Nagoya, Japan: Author.

Wachs, M. (1982). Ethical dilemmas in forecasting for public policy. Public Administration Review, 42, $562-567$.

Webster, C. J. (1993). GIS and the scientific inputs to urban planning. Part 1: Description. Environment and Planning, $B$ : Planning and Design, 20(6), 709-728.

Webster, C. J. (1994). GIS and the scientific inputs to urban planning. Part 2: Prediction and prescription. Environment and Planning, B: Planning and Design, 21, 145-157.

Weizenbaum, J. (1976). Computer power and human reason: From judgement to calculation. New York: W. H. Freeman.

Werle, J. W. (1984). Problems in automating traditional land records data. Computers, Environment and Urban Systems, 9, 199-202.

Wiggins, L. L., \& French, S. P. (1991). GIS: Assessing your needs and choosing a system. Chicago: American Planning Association.

Worrall, L. (1989). Urban planning process and strategic information systems. In A. G. O. Yeh (Ed.), Proceedings, International Conference on Computers in Urban Planning and Management (pp. 123-134). Hong Kong: Centre of Urban Studies and Urban Planning, University of Hong Kong.

Yapa, L. S. (1988). Computer-aided regional planning: A study in rural Sri Lanka. Environment and Planning, R: Planning and Design, 15, 285-304.

Yapa, L. S. (1989). Low-cost map overlay analysis using computer-aided design. Environment and Planning, B: Planning and Design, 16, 377-392.

Yeh, A. G. (1991). Strategies of GIS development for urban and regional planning in developing countries. In R. E. Klosterman (Ed.), Proceedings, Second International Conference on Computers in Urban Planning and Urban Management (Vol. 2, pp. 127-129). Akron, OH: Institute for Computer-Aided Planning.

Zwart, P., \& Williamson, I. (1988). Parcel-based land information systems in planning. In P. W. Newton, M. A. P. Taylor, \& R. Sharpe (Eds.), Desktop planning: Microcomputer applications for infrastructure and services planning and management. Melbourne: Hargreen. 